\title{
Administration of Folium mori Extract Decreases Nitric Oxide Synthase Expression in the Hypothalamus of Streptozotocin-Induced Diabetic Rats
}

\author{
Mi-Hyeon Jang ${ }^{1}$, Hong Kim ${ }^{1,2}$, Min-Chul Shin ${ }^{1}$, Baek-Vin Lim ${ }^{1}$, Taeck-Hyun Lee ${ }^{1}$, \\ Sae-Bin Jung ${ }^{1}$, Chang-Ju Kim ${ }^{1}$ and Ee-Hwa Kim ${ }^{3} *$ \\ ${ }^{1}$ Department of Physiology, College of Medicine, Kyung Hee University, Seoul, Korea \\ ${ }^{2}$ Research Institute of Sports Science, Korea University, Seoul, Korea \\ ${ }^{3}$ Department of Meridianology, College of Oriental Medicine, Semyung University, Jechon, Korea
}

Received June 21, 2002 Accepted July 26, 2002

\begin{abstract}
Folium mori, the leaves of Morus alba L., has traditionally been used for the treatment of diabetic hyperglycemia. It has been shown to induce enhanced NOS expression in the hypothalamus of rats with streptozotocin (STZ)-induced diabetes. In the present study, the effect of Folium mori on the expression of nitric oxide synthase (NOS) in the hypothalamus of STZ-induced diabetic rats was investigated via nicotinamide adenine dinucleotide phosphate-diaphorase (NADPH-d) histochemistry. Enhanced NAPDH-d expression was detected in the paraventricular nucleus, ventromedial hypothalamic nucleus, and lateral hypothalamic area of the hypothalamus in the STZ-induced diabetes group. Administration of the aqueous extract of Folium mori to rats with STZ-induced diabetes resulted in decreased NADPH-d positivity. These results suggest that Folium mori treatment is effective in curbing the desire for food under diabetic conditions via modulation of $\mathrm{NO}$ expression in the hypothalamus.
\end{abstract}

Keywords: Folium mori, Streptozotocin-induced diabetes, Nitric oxide synthase

Diabetes mellitus is one of the most common metabolic disorders in humans. In addition to the diabetic condition itself, numerous secondary complications are associated with the illness (1). It is characterized by marked hyperphagia, reduced thermogenesis, and impaired secretion of most pituitary hormones (2). As the hypothalamus appears to be important in the regulation of food intake and energy balance, these energetic and neuroendocrine disturbances seen in diabetes may be mediated by changes in the levels and distributions of specific hypothalamic neurons and neurotransmitters (3).

Nitric oxide (NO), synthesized from L-arginine by nitric oxide synthase (NOS), acts as a neurotransmitter and a biological messenger molecule in the brain and other mammalian tissues $(4,5)$. NO is also known to be a modulator in the regulation of food intake. Numerous studies have reported that pharmacological inhibition of NOS results in suppressed food intake $(6,7)$. In addition, it has been documented that administration of NOS inhibitors to

*Corresponding author. FAX: +82-43-649-1349

E-mail: Kimeh@semyung.ac.kr genetically obese Zucker $(f a / f a)$ rats results in a decrease in food intake $(8,9)$. These findings indicate that NO may play a role in the regulation of food intake.

Folium mori, the leaves of Morus alba L., is one of the best known Oriental medicinal herbs, and medications based on Folium mori have been found to be useful in the treatment of diabetic hyperglycemia $(10,11)$. However, no study on the effect of Folium mori on the activity of hypothalamic neurons containing NOS in streptozotocin (STZ)induced diabetic rat has been made yet. In the present study, in order to investigate the effect of the aqueous extract of Folium mori on the expression of NOS in the hypothalamus, we employed NADPH-d histochemistry, which takes advantage of the fact that NADPH-d-positive neurons are the same as those containing NOS (12).

Male Sprague-Dawley rats weighing $200 \pm 10 \mathrm{~g}$ ( 6 weeks of age) were used for the experiment. Each animal was housed at a controlled temperature $\left(20 \pm 2^{\circ} \mathrm{C}\right)$ and was maintained under light-dark cycles, each cycle consisting of $12 \mathrm{~h}$ of light and $12 \mathrm{~h}$ of darkness (lights on from 07:00 h to 19:00 h), with food and water made available ad libitum. The experimental procedures were conducted in accor- 
dance with the Guiding Principles for the Care and Use of Laboratory Animals approved by The Japanese Pharmacological Society and the Korean Academy of Medical Sciences. Animals were divided into eight groups: the control group, the nondiabetic and $10 \mathrm{mg} / \mathrm{kg}$ Folium mori-treated group, the nondiabetic and $50 \mathrm{mg} / \mathrm{kg}$ Folium mori-treated group, the nondiabetic and $100 \mathrm{mg} / \mathrm{kg}$ Folium mori-treated group, the streptozotocin (STZ)-induced-diabetes group, the STZ-induced-diabetes and $10 \mathrm{mg} / \mathrm{kg}$ Folium moritreated group, the STZ-induced-diabetes and $50 \mathrm{mg} / \mathrm{kg}$ Folium mori-treated group, and the STZ-induced-diabetes and $100 \mathrm{mg} / \mathrm{kg}$ Folium mori-treated group ( $\mathrm{n}=5$ for each group). To induce diabetes in the experimental animals, a single intraperitoneal injection of STZ $(50 \mathrm{mg} / \mathrm{kg}$, in saline; Sigma Chemical Co., St. Louis, MO, USA) was given to each animal, and animals of the control and the non-diabetic group received equivalent amounts of normal saline. Blood glucose levels were determined 2 days after streptozotocin injection using a blood glucose analyzer (Arkray, Kyoto). Only the animals with blood glucose levels of $300 \mathrm{mg} / \mathrm{dl}$ or higher were used in this study. Animals of the Folium mori-treated groups were injected intraperitoneally with the aqueous extract of Folim mori at the respective dose for 3 days.

To obtain the aqueous extract of Folium mori, $200 \mathrm{~g}$ of Folium mori was added to distilled water, and extraction was performed by heating at $80^{\circ} \mathrm{C}$; then the extract was concentrated with a rotary evaporator and lyophilized. The resulting powder, weighing $30 \mathrm{~g}$ (a collection rate of 15\%), was diluted with saline.

For the sacrificial process, animals were first weighed and overdosed with Zoletil $50^{\circledR}(10 \mathrm{mg} / \mathrm{kg}$, i.p.; Vibac Laboratories, Carros, France). After a complete lack of response was observed, the rats were transcardially perfused with $50 \mathrm{mM}$ phosphate-buffered saline (PBS) and then with $4 \%$ paraformaldehyde in $100 \mathrm{mM}$ phosphate buffer (PB) at $\mathrm{pH}$ 7.4. The brains were dissected, postfixed in the same fixative overnight, and transferred into a $30 \%$ sucrose solution for cryoprotection. Serial coronal sections of $40-\mu \mathrm{m}$ thickness were made using a freezing microtome (Leica, Nussloch, Germany). Sections were then stained for NADPH-d activity according to the previously described protocol (13). In brief, free-floating sections were incubated at $37^{\circ} \mathrm{C}$ for $1 \mathrm{~h}$ in $100 \mathrm{mM}$ PB containing $0.3 \%$ Triton $\mathrm{X}$ $100,0.1 \mathrm{mg} / \mathrm{ml}$ nitroblue tetrazolium, and $0.1 \mathrm{mg} / \mathrm{ml} \beta$ NADPH. The sections were then washed three times with PBS and mounted onto gelatin-coated slides. The slides were air dried overnight at room temperature, and coverslips were mounted using Permount ${ }^{\mathbb{R}}$. The staining intensities of the processed sections were assessed in a quantitative fashion according to a microdensitometrical method based on optical density using an image analyzer (Multiscan, Fullerton, CA, USA).
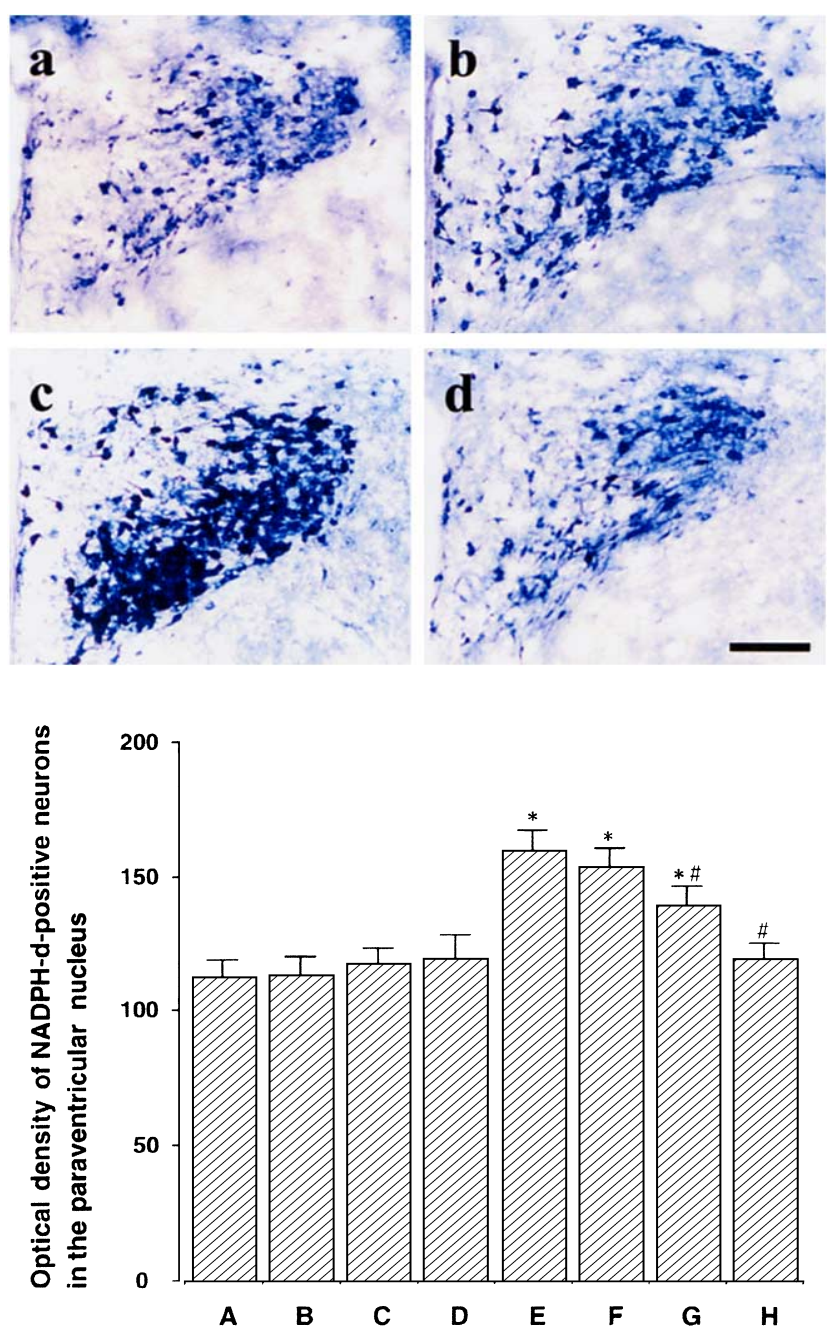

Fig. 1. Effect of Folium mori on the expression of nitric oxide synthase in the paraventricular nucleus (PVN). Above: Photomicrographs of nicotinamide adenine dinucleotide phosphate-diaphorase (NADPH-d)-positive neurons in the PVN of the hypothalamus in each group. a, control group; b, non-diabetic and $100 \mathrm{mg} / \mathrm{kg}$ Folium mori-treated group; c, streptozotocin (STZ)-induced-diabetes group; $\mathrm{d}$, STZ-induced-diabetes and $100 \mathrm{mg} / \mathrm{kg}$ Folium mori-treated group. Scale bar represents $100 \mu \mathrm{m}$. Below: Mean optical density of NADPH-d-positive neurons in the PVN of the hypothalamus in each group. Values are represented as the mean \pm S.E.M. $*$ represents $P<0.05$ compared to the control group. ${ }^{\#}$ represents $P<0.05$ compared to the STZ-induced diabetes group. A, control group; B, non-diabetic and $10 \mathrm{mg} / \mathrm{kg}$ Folium mori-treated group; C, non-diabetic and $50 \mathrm{mg} / \mathrm{kg}$ Folium mori-treated group; D, non-diabetic and $100 \mathrm{mg}$ $/ \mathrm{kg}$ Folium mori-treated group; E, STZ-induced-diabetes group; F, STZ-induced-diabetes and $10 \mathrm{mg} / \mathrm{kg}$ Folium mori-treated group; G, STZ-induced-diabetes and $50 \mathrm{mg} / \mathrm{kg}$ Folium mori-treated group; $\mathrm{H}, \mathrm{STZ}$-induced-diabetes and $100 \mathrm{mg} / \mathrm{kg}$ Folium mori-treated group.

Statistical differences were determined by one-way analysis of variance (ANOVA) followed by Scheffe's Post-hoc test, and results are expressed as the mean \pm S.E.M. Differences were considered significant for $P<0.05$.

As shown in Figs. 1-3, expression of NADPH-d in the 

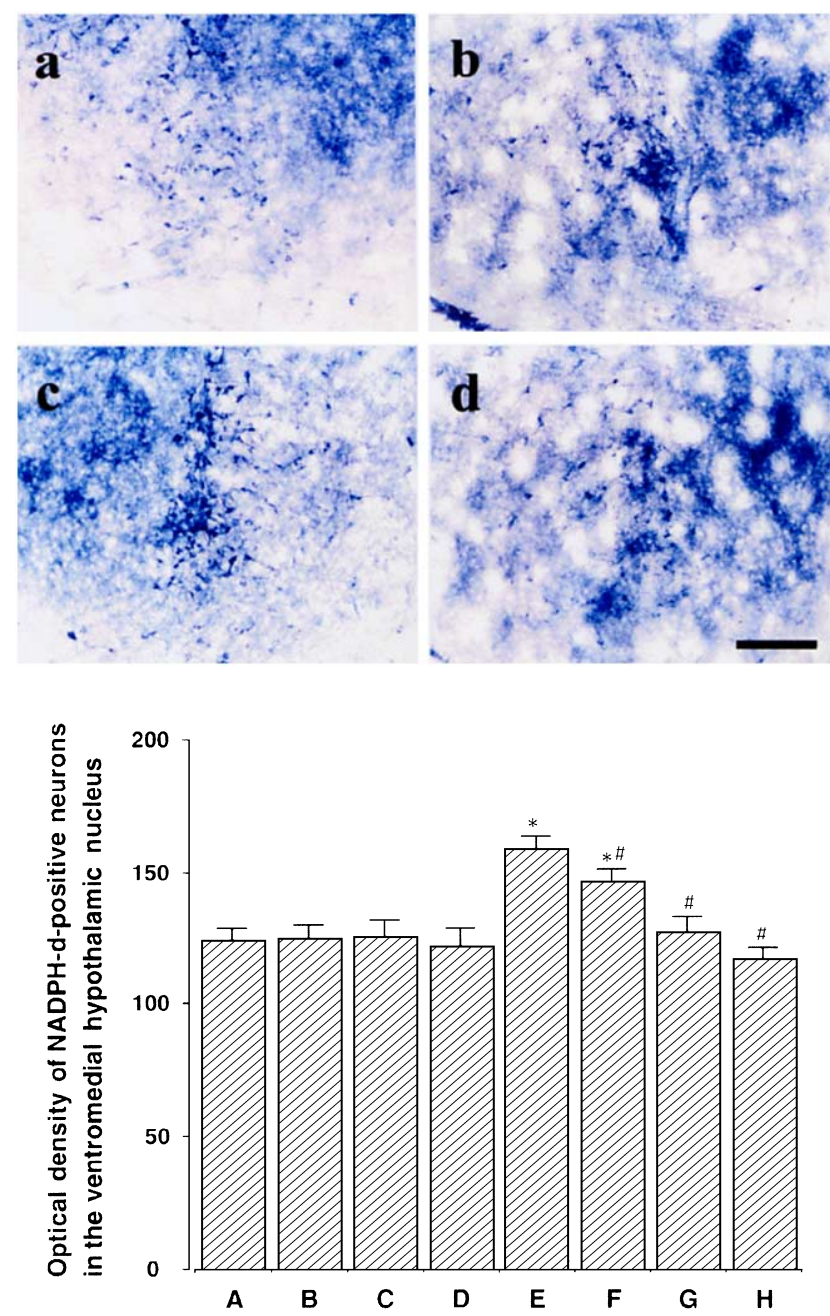

Fig. 2. Effect of Folium mori on the expression of nitric oxide synthase in the ventromedial hypothalamic nucleus (VMH). Above: Photomicrographs of nicotinamide adenine dinucleotide phosphatediaphorase (NADPH-d)-positive neurons in the VMH of the hypothalamus in each group. See Fig. 1. for the experimental group labels. Scale bar represents $100 \mu \mathrm{m}$. Below: Mean optical density of NADPH-d-positive neurons in the VMH of the hypothalamus in each group. Values are represented as the mean \pm S.E.M. * represents $P<0.05$ compared to the control group. ${ }^{\#}$ represents $P<0.05$ compared to the STZ-induced diabetes group. See Fig. 1. for the experimental group labels.

PVN, VMH and LHA regions of the hypothalamus was increased in rats with STZ-induced diabetes. Folim mori treatment suppressed the diabetes-induced increase in NOS expression dose-dependently, with the optical density of NADPH-d-positive neurons reaching a level comparable to the control value in all regions of the hypothalamus studied in the STZ-induced-diabetes and $100 \mathrm{mg} / \mathrm{kg}$ Folium moritreated group; however, this treatment did not have any significant effect on nondiabetic rats.

In the present study, higher staining intensities were observed in the PVN, VMH and LHA of the STZ-induced
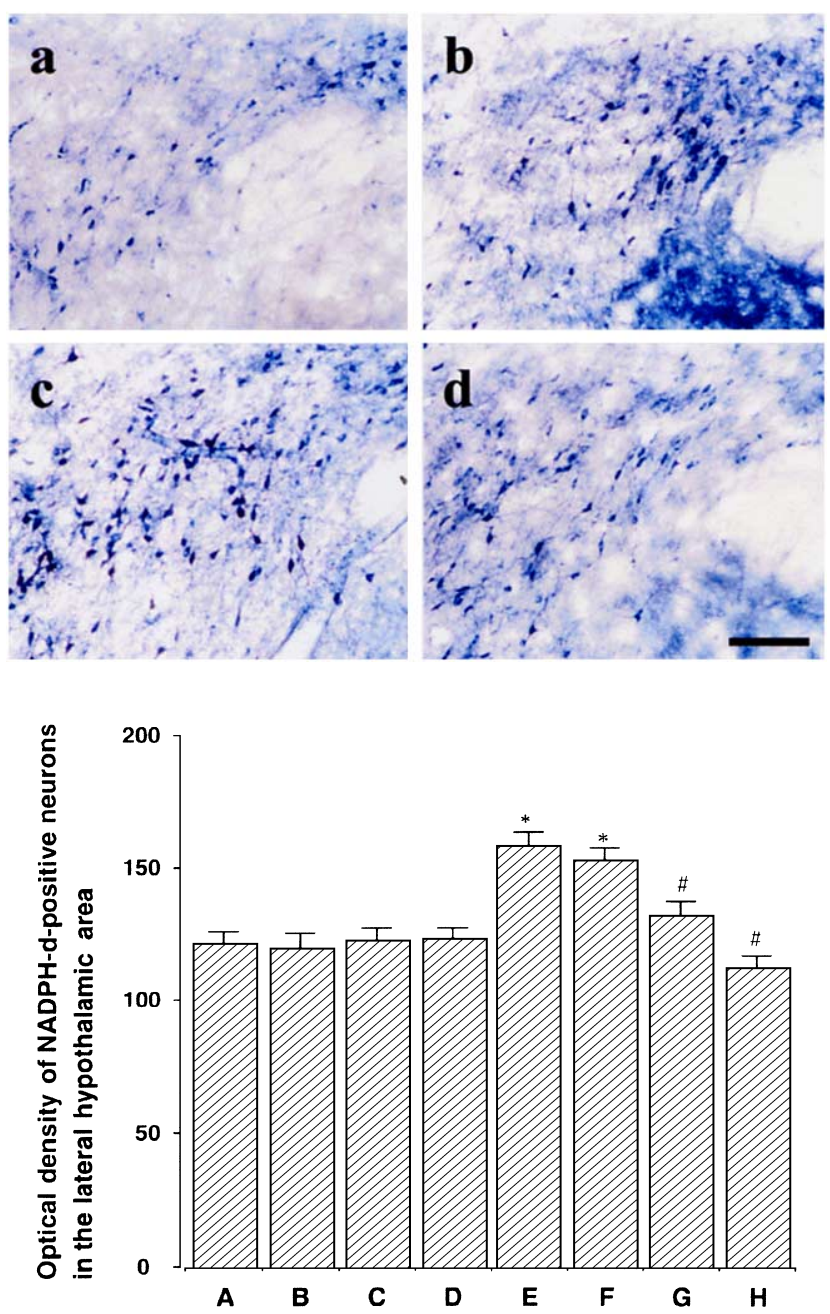

Fig. 3. Effect of Folium mori on the expression of nitric oxide synthase in the lateral hypothalamic area (LHA). Above: Photomicrographs of nicotinamide adenine dinucleotide phosphate-diaphorase (NADPH-d)-positive neurons in the LHA of the hypothalamus in each group. See Fig. 1. for the experimental group labels. Scale bar represents $100 \mu \mathrm{m}$. Below: Mean optical density of NADPH-dpositive neurons in the LHA of the hypothalamus in each group. Values are represented as the mean \pm S.E.M. ${ }^{*}$ represents $P<0.05$ compared to the control group. ${ }^{\#}$ represents $P<0.05$ compared to the STZ-induced diabetes group. See Fig. 1. for the experimental group labels.

diabetes group compared to the control group. NADPH-dpositivity in the PVN, VMH and LHA of the STZ-induced diabetes group was in turn significantly decreased by administration of the aqueous extract of Folium mori in a dose-dependent manner. In contrast, the intensities under normal conditions was not affected by administration of Folium mori. The arcuate nucleus did not stain positively for NADPH-d, as was reported previously in Wistar rats (14).

It is known that $\mathrm{NO}$ acts a as mediator in the modulatory mechanism of feeding and appetite, like other orexigenic 
agents such as norepinephrine, neuropeptide Y (NPY), and galanin (6). It has been suggested in various studies that NO may regulate feeding behavior, and administration of NOS inhibitors was shown to result in suppressed food intake in food-deprived animals $(6,7)$.

Peripheral administration of STZ causes marked hyperglycemia, hyperphagia and polydipsia, and insulin treatment reverses these symptoms (3). Numerous studies have shown that insulin deficiency-induced diabetes causes alteration in the activities of hypothalamic transmitters and neuropeptides (3, 15); Serino et al. (3) demonstrated that enhanced NOS gene expression takes place in the hypothalamus in rats with STZ-induced diabetes.

Medications based on Folium mori have traditionally been used for the treatment of diabetes. Folium mori is known to possess properties such as raising insulin sensitivity (11) and inducing hypoglycemia (10). However, no report to date has been made on the effect of Folium mori on NOS activity in the hypothalamus. In the present study, it was demonstrated that the aqueous extract of Folium mori is effective in limiting the enhancement in NOS expression accompanying STZ-induced diabetes. Based on the results, it can be suggested that Folium mori treatment is effective in curbing the desire for food in diabetic conditions due to its modulatory effect on NOS expression in the hypothalamus.

\section{Acknowledgment}

This work was supported by grant No. R05-2001-000-00445-0 from the basic research program of the Korea Science \& Engineering Foundation.

\section{REFERENCES}

1 Jackson-Guilford J, Leander JD and Nisenbaum LK: The effect of streptozotocin-induced diabetes on cell proliferation in the rat dentate gyrus. Neurosci Lett 293, 91 - 94 (2000)

2 Frankish HM, Dryden S, Hopkins D, Wang Q and Williams G: Neuropeptide Y, the hypothalamus and diabetes: Insights into the central control of metabolism. Peptides 16, 757 - 771 (1995)

3 Serino R, Ueta Y, Tokunaga M, Hara Y, Nomura M, Kabashima N, Shibuya I, Hattori Y and Yamashita H: Upregulation of hypo- thalamic nitric oxide synthase gene expression in streptozotocininduced diabetic rats. Diabetologia 41, 640 - 648 (1998)

4 Dawson TM, Dawson VL and Snyder SH: A novel neuronal messenger molecule in brain: the free radical, nitric oxide. Ann Neurol 32, 297 - 311 (1992)

5 Moncada S: The L-arginine: nitric oxide pathway. Acta Physiol Scand 145, 201 - 227 (1992)

6 Morley JE and Flood JF: Evidence that nitric oxide modulates food intake in mice. Life Sci 49, 707 - 711 (1991)

7 Squadrito F, Calapai G, Altavilla D, Cucinotta D, Zingarelli B, Campo GM, Arcoraci V, Sautebin L, Mazzaglia G and Caputi AP: Food deprivation increases brain nitric oxide synthase and depresses brain serotonin levels in rats. Neuropharmacology 33, 83 - 86 (1994)

8 Kim MJ, Kim Y, Choe BK, Kim SA, Lee HJ, Kim JW, Huh Y, Kim CJ and Chung JH: Differential expression of nicotineamide adenine dinucleotide phosphate-diaphorase in hypothalamic areas of obese Zucker rats. Neurosci Lett 292, 60 - 62 (2000)

9 Stricker-Krongrad A, Beck B and Burlet C: Nitric oxide mediates hyperphagia of obese Zucker rats: relation to specific changes in the microstructure of feeding behavior. Life Sci 58, PL9 - PL15 (1996)

10 Andallu B, Suryakantham V, Srikanthi BL and Reddy GK: Effect of mulberry (Morus indica L.) therapy on plasma and erythrocyte membrane lipids in patients with type 2 diabetes. Clin Chim Acta 314, 47 - 53 (2001)

11 Chen F, Nakashima N, Kimura I, Kimura M, Asano N and Koya $\mathrm{S}$ : Potentiating effects on pilocarpine-induced saliva secretion, by extracts and $\mathrm{N}$-containing sugars derived from mulberry leaves, in streptozotocin-diabetic mice. Biol Pharm Bull 18, 1676 - 1680 (1995)

12 Hope BT, Michael GJ, Knigge KM and Vincent SR: Neuronal NADPH diaphorase is a nitric oxide synthase. Proc Natl Acad Sci USA 88, 2811 - 2814 (1991)

13 Jang MH, Shin MC, Lim BV, Chung JH, Kang HS, Kang SA, Choue RW, Kim EH and Kim CJ: Nicotine administration decreases nitric oxide synthase expression in the hypothalamus of food-deprived rats. Neurosci Lett 322, 29 - 32 (2002)

14 Vincent SR and Kimura H: Histochemical mapping of nitric oxide synthase in the rat brain. Neuroscience 46, 755-784 (1992)

15 Sipols AJ, Baskin DG and Schwartz MW: Effect of intracerebroventricular insulin infusion on diabetic hyperphagia and hypothalamic neuropeptide gene expression. Diabetes 44, $147-$ 151 (1995) 